\title{
EFECTOS DE LA FERTILIZACIÓN FOSFORADA SOBRE LA PRODUCCIÓN DE MINITUBERCULOS DE PAPA (Solanum tuberosum L) EN INVERNADERO
}

\author{
Beatriz Giorgetta*; Patricio Dallari*; Mario Buteler**
}

\section{RESUMEN}

El objetivo de este trabajo fue determinar la dosis de fósforo (P) apropiada para la producción de minitubérculos de papa (Solanum tuberosum L.) cv. Spunta, libres de virus, en camas bajo invernadero, y empleando un sustrato compuesto por arena, perlita y mantillo de monte en relación 1:1:2 v/v.

Para ello se plantearon dos experimentos de cuatro y seis tratamientos cada uno. En el primero se aplicaron dosis de 0 y $60 \mathrm{~g} / \mathrm{m}^{2}$ de P sobre parcelas con y sin plantas; y en el segundo: 10, 20, 40, 60, 80 y $150 \mathrm{~g} / \mathrm{m}^{2}$ de P. Se analizó i) la variación de $\mathrm{pH}$ y concentración de $\mathrm{P}$ en el sustrato a lo largo del ciclo y ii) la relación entre las dosis aplicadas.

El pH, el contenido de $\mathrm{P}$ en el sustrato, el nivel foliar y la producción de minitubérculos totales y clasificados en cinco intervalos de peso.

La producción máxima alcanzada fue de $4.3 \mathrm{~kg} / \mathrm{m}^{2}$ (385 minitubérculos totales, el $53 \%$ pesó entre 5 y $40 \mathrm{~g}$ ) para una dosis de $20 \mathrm{~g}$ de $\mathrm{P} / \mathrm{m}^{2}$ aplicado como superfosfato triple. A esta dosis el nivel de disponibilidad fue de $72 \mathrm{ppm}(\mathrm{pH}=$ 6.9) y el foliar de $0.60 \%$ P/P seco. Dosis mayores produjeron un efecto perjudicial en la producción.

Palabras claves adicionales: sustrato, fósforo, $\mathrm{pH}$.

Aceptado para publicación: marzo 2, 1993

* Lic. Fisico-Qco., Química General e Inorgánica. Facultad de Ciencias Agropecuarias.

** Ings. Agrs., Agricultura Facultad de Ciencias Agropecuarias. C.C. 500 - Córdoba - 5000 Argentina. 


\section{SUMMARY}

\section{EFFECT OF PHOSPHORUS FERTILIZATION ON THE PRODUCTION OF MINITUBERS UNDER GREENHOUSE CONDITIONS}

The objective of this work was to define the most appropriate phosphorus (P) fertilization rate toward the production of virus free potato minitubers (Solanum tuberosum L. cv. Spunta) on beds under glasshouse. The bed substrate used was composed of sand. perlite and forest mould in 1:1:2 by volume ratio. Two experiments were carried out with four and six treatments each, respectively. In the first one the $\mathrm{P}$ rates applied were $\mathrm{O}$ and $60 \mathrm{~g} / \mathrm{m}^{2}$ on plots with and without potato plants; and in the second one $10 ; 20 ; 40 ; 80 ; 150 \mathrm{~g} / \mathrm{m}^{2}$ of P were applied. The data analysis was performed in order to determine i) the substrate $\mathrm{pH}$ a $\mathrm{P}$ contents changes along the plant cycle and ii) the effects of the $\mathrm{P}$ rate used on $\mathrm{pH}$ and $\mathrm{P}$ substrate levels, $\mathrm{P}$ total leaf content, total minituber yield and minituber yield in five tuber weight ¡intervals. The highest yield achieved was $4,3 \mathrm{~kg} / \mathrm{m}^{2}$ (385 minitubers, $53 \%$ between $5-40 \mathrm{~g}$ ) with $20 \mathrm{~g} / \mathrm{m}^{2}$ of P supplied as triple superphosfate. With this treatment the substrate P availability was $72 \mathrm{ppm}$ $(\mathrm{pH}=6,9)$ and the leaf content $0.60 \%$ on a dry weight basis. Higher $\mathrm{P}$ rates showed deleterious effects upon the yield.

Additional index words: substrate, phosphorous, $\mathrm{pH}$.

La Facultad de Ciencias Agropecuarias inició a principios de la década del 80 trabajos tendientes a desarrollar las bases tecnológicas para la obtención de semilla pre-básica y básica de papa (Solanum tuberosum L.), para transferirlas al sector productivo de la provincia de Córdoba Argentina. Se diseñó un sistema integrado consistente en una etapa de micropropagación in vitro (saneamiento por termoterapia, cultivo de meristemas y multiplicación por microesquejes); posterior etapa de multiplicación bajo condiciones de forzadura total (trasplantes de microplantas en altas densidades a cama en invernadero para obtención de minitubérculos); y por último una tercera etapa de multiplicación a campo en zonas aisladas (multiplicación de minitubérculos) $(3,15)$.

Para obtener una alta tasa de multiplicación en la 2da etapa (obtención de minitubérculos en invernadero) se requiere controlar diversos factores de los cuales la calidad físico-química del sustrato, densidad de plantación, régimen de riego, manejo cultural y sanitario, han sido fijados $(4,5)$. Estos deben ser complementados de acuerdo a un régimen de fertilización adecuado a los requerimientos del cultivo y al comportamiento del sustrato confinado. 
Los requerimientos de nutrientes de este cultivo son aparentemente los mismos en calidad que para cualquier otro, pero son altos en cantidad por su ciclo corto y alta producción de materia seca $(6,7,12)$. Existen abundantes antecedentes en cuanto a las dosis de nutrientes principales a emplear en el campo $(6,7,9,19)$, y escasos para cultivos densos en camas bajo condiciones de invernadero $(20,21)$. Los rangos aconsejados para campo dependen del cultivar y de las condiciones edáfico-climáticas, mientras los citados para invernadero se relacionan exclusivamente al empleo de turba como componente orgánico del sustrato y a la producción de semilla sexual o de minitubérculos a partir de ella Son muy escasos los antecedentes de fertilización con azufre, calcio, magnesio y micro nutrientes (13)

En el sistema de producción empleado, las condiciones son particulares en varios aspectos: i) el sustrato apto (5) ha sido seleccionado a partir de materiales disponibles como mantillo de monte en reemplazo de turba (4), siendo desconocido su comportamiento nutricional; ii) el producto deseado es un alto número de minitubérculos de peso comprendido entre 5-40 g; iii) los requerimientos específicos de la variedad empleada sólo han sido someramente estudiados para papa consumo en condiciones de campo (7).

En los antecedentes referidos a la fertilización del cultivo con nutrientes mayores, para el fósforo $(\mathrm{P})$ existe mayor coincidencia en cuanto al tiempo de aplicación (7) y se conoce su influencia sobre la disponibilidad de los otros por posible efecto sobre el $\mathrm{pH}$ y capacidad buffer del sustrato. El cálculo de la dosis de fertilizante fosforado para un sustrato depende del nivel de disponibilidad inicial de su comportamiento en cuanto a pérdidas por lavado o inmovilización por fijación al sustrato, como de la cantidad de materia seca producida por unidad de superficie (20). Su comportamiento ha sido estudiado sobre determinados suelos $(1,17)$ y sobre algunos materiales orgánicos tales como turbas aserrín corteza de pino $(8,11,14,24)$ incluso con propuestas metodológicas para su análisis $(2,11,18)$.

Se considera que la disponibilidad de $\mathrm{P}$ es afectada por el $\mathrm{pH}$ del sustrato $(7,17)$ y que éste puede ser disminuido con la aplicación de superfosfato triple (1). Bajo la hipótesis de que la capacidad de reserva del sustrato es baja y que la adición de superfosfato produce un incremento de la fertilidad en ambos factores: capacidad e intensidad (concentración del nutriente en la solución del sustrato); se plantea como objetivo de este trabajo analizar los efectos de la fertilización fóforada sobre el $\mathrm{pH}$, la disponibilidad de $\mathrm{P}$ en el sustrato y sus relaciones con el nivel de $\mathrm{P}$ en las hojas y la producción deseada.

\section{MATERIALES Y MÉTODOS}

Se realizaron dos experimentos en invernadero de cobertura plástica traslúcida sobre un sustrato compuesto por mantillo de monte, arena y perlita en relación 2:1:1 v/v caracterizado por pH: 7,2 (en agua 1:2) 6,2 \% de 
Materia Orgánica (Walkey-Black) y densidad 0,92 g/cc.

Se utilizaron microplantas del cultivar Spunta trasplantadas en parcelas de cuatro hileras dispuestas bajo un arreglo completamente aleatorizado con cuatro repeticiones por tratamiento. La superficie de cada unidad experimental fue de $0,5 \mathrm{~m}^{2}$ y se aislaron entre sí mediante láminas de polietileno, adoptando una densidad de trasplante de 78 plantas $/ \mathrm{m}^{2}$. Las plántulas se trasplantaron el 01/03/89 y la cosecha se realizó 105 días después. Las prácticas culturales empleadas fueron las usuales para el cultivo, manteniendo la humedad del sustrato dentro de los límites de agua fácilmente utilizable (5).

Los fertilizantes empleados fueron: Urea (N), Superfosfato Triple (P3) y Cloruro de Potasio (K). Se aplicó el $\mathrm{P}$ a los 37 días, $\mathrm{K}$ a los 60 días y el N se dividió en dos aplicaciones: 1/4 de la dosis a los 40 días y 3/4 a los 56 días posteriores a la fecha del trasplante. La primera aplicación (37 días) se realizó en un único riego una vez que las plántulas enraizaron.

\section{Experimento 1}

Consistió en cuatro tratamientos descritos en la Tabla 1. De las parcelas correspondientes a estos tratamientos se tomaron tres submuestras de sustrato cada 7 días con un tubo de muestreo de $65 \mathrm{~cm}$ formando una muestra compuesta. Los resultados de los análisis de nutrientes publicados muestran gran variabilidad según el método de extracción empleado (11), en consecuencia se adoptó el método de Fisons (2) por ser el más conveniente para manejar un alto número de muestras sin demasiados requisitos de infraestructura. Este método consiste en una extracción acuosa 1:6 v/v dilución que no requiere determinación previa de humedad eliminando así una importante fuente de variabilidad. Sobre cada extracto de sustrato se determinó $\mathrm{pH}$ potenciométricamente y $\mathrm{P}$ por el método del Azul de molibdeno (22).

Tabla 1. Tratamientos correspondientes al experimento 1.

\begin{tabular}{lcccc}
\hline & $\begin{array}{c}\text { Tratamiento } \\
\mathrm{N}^{\mathrm{o}}\end{array}$ & $\mathrm{N}$ & $\mathrm{P}$ & $\mathrm{K}$ \\
\hline Con & 1 & 0 & 0 & 0 \\
Plantas & 3 & 40 & 60 & 40 \\
\hline Sin & 2 & 0 & 0 & 0 \\
Plantas & 4 & 40 & 60 & 40 \\
\hline
\end{tabular}

\section{Experimento 2}

Consistió en seis tratamientos descritos en la Tabla 2. De cada tratamiento se tomaron muestras de sustrato y hojas a los 50 y 64 días posteriores al trasplante. Para el primero se empleó la técnica de muestreo y extracción 
antes descrita y en el segundo caso se utilizó la cuarta hoja completamente expandida comenzando por el ápice del tallo principal de 10 plantas tomadas al azar de las hileras centrales conformando una muestra compuesta. Estas fueron secadas durante $24 \mathrm{~h}$ a $60{ }^{\circ} \mathrm{C}$ molidas en un molinillo tipo Wiley lamizadas (20 mesh) y digeridas en $\mathrm{H}_{2} \mathrm{SO}_{4}: \mathrm{H}_{2} \mathrm{O}_{2}$ (23). Sobre cada extracto foliar resultante se determinó $\mathrm{P}$ por el método del Azul de molibdeno y se siguieron las mismas técnicas de determinación planteadas en el Experimento 1 para los extractos de sustrato $(22,23)$.

Tabla 2. Tratamientos correspondientes al experimento 2.

\begin{tabular}{|cccc|}
\hline $\begin{array}{c}\text { Tratamiento } \\
\mathrm{N}^{\circ}\end{array}$ & $\mathrm{N}$ & $\begin{array}{c}\text { Dosis g/m } \\
\mathrm{P}\end{array}$ & $\mathrm{K}$ \\
\hline 1 & 20 & 10 & 20 \\
3 & 20 & 20 & 20 \\
2 & 20 & 40 & 20 \\
4 & 20 & 60 & 20 \\
5 & 20 & 80 & 20 \\
6 & 20 & 150 & 20 \\
\hline
\end{tabular}

En ambos experimentos se realizó la cosecha a los 105 días determinándose peso y número total de minitubérculos/m2 y su distribución dentro de los siguientes intervalos de peso: $<5,5-10.10-20,20-40$ y $>40$ g. Los resultados fueron analizados mediante la técnica del Análisis de la Varianza luego de corroborados sus supuestos, empleándose el test de Duncan para comparaciones múltiples entre medias de tratamientos $(\mathrm{P}<0.05)$. Sobre los datos del experimento 1 se aplicó la técnica de Análisis Multivariado de la Varianza con repeticiones en el tiempo.

\section{RESULTADOS Y DISCUSIÓN}

\section{Experimento 1}

Los contenidos de $\mathrm{P}$ e $\mathrm{H}^{+}(\mathrm{pH})$ en el sustrato a lo largo del ciclo del cultivo se informan en las Figuras 1 y 2. respectivamente.

En la Figura 1 se observa que los niveles residuales de $\mathrm{P}$ en las parcelas sin fertilizar se mantienen constantes durante el ciclo poniendo de manifiesto la capacidad de reserva del sustrato, aunque con baja intensidad (rango observado 5-11 ppm); este comportamiento es semejante al de un suelo natural (18). En las parcelas fertilizadas. Las medias de los tratamientos (con cultivo y sin cultivo) muestran una tendencia paralela con diferencias altamente significativas $(\mathrm{P}<0.01)$ en fechas inmediatamente posteriores a la fertilización fosforada (cuando se produce la fijación al sustrato) y al final del ciclo de observación. El proceso de fijación al sustrato aparenta ser más 
rápido e intenso en las parcelas carentes de cultivo, probablemente debido al método de aplicación del fertilizante (riego) que causa retención del elemento en la cobertura vegetal. Al final del ciclo la diferencia es causada por la absorción del nutriente por el cultivo; bajo esta hipótesis, del valor numérico de la diferencia puede estimarse la absorción en $10 \mathrm{~g}$ de $\mathrm{P} / \mathrm{m}^{2}$ para una producción de 2,6 Kg de minitubérculos $/ \mathrm{m}^{2}$.

La fijación de $\mathrm{P}$ al sustrato es deseable, pues disminuye las pérdidas por lavado, siendo probable, dadas las condiciones del sustrato (presencia de calcio y pH próximo a la neutralidad), que el mecanismo de precipitación como fosfatos cálcicos sea el predominante en la fijación que se produce dentro de las primeras 5 semanas posteriores a la incorporación del superfosfato. Este comportamiento del sustrato es semejante al observado en un suelo natural de reacción neutra $(1,17)$, siendo su capacidad de retención mayor que las informadas para turbas $(8,14)$. En relación a la corteza de pino la retención es mucho menor pero el proceso de fijación es más rápido $(14,24)$ permitiendo controlar y sostener el factor intensidad con menores dosis de superfosfato triple.

El $\mathrm{pH}$ del sustrato es alto $(7.5-7,6)$ al comienzo del experimento. La disminución del $\mathrm{pH}$ observada en la Figura 2 sólo es estadísticamente significativa $(\mathrm{P}<0,01)$ en las parcelas fertilizadas siendo más pronunciada $(\mathrm{P}<0,01)$ en las carentes de cultivo donde el cambio supera una unidad de $\mathrm{pH}$. La magnitud del cambio permite deducir la existencia de una escasa capacidad buffer del sustrato, si bien la contribución del componente orgánico a la capacidad reguladora es alta en un suelo natural ésta se ve fuertemente disminuida cuando se altera la estructura para formar un sustrato artificial $(2,18)$. El efecto producido por el superfosfato triple ha sido descrito para sucios naturales (1) y corteza de pino (8), y es deseable en esta situación porque permite alcanzar un $\mathrm{pH}$ óptimo, que para este cultivo está considerado dentro del rango 5,5-6,5 (7,20). El comportamiento observado para el $\mathrm{pH}$ se corresponde con los contenidos de fósforo en las parcelas respectivas y con la escasa capacidad reguladora del sustrato.

\section{Experimento 2}

Efectos sobre el pH y nivel de $\mathbf{P}$ en el sustrato: Los contenidos de $\mathrm{P}$ asimilables y $\mathrm{pH}$ del sustrato medidos en dos fechas posteriores a la fertilización (13 y 27 días) con dosis crecientes entre 10 y 150 g de $\mathrm{P} / \mathrm{m}^{2}$ se informan en la Tabla 3. No existen diferencias significativas entre fechas $(\mathrm{P}<0,05)$ por lo que se presentan los correspondientes a la segunda, que muestran menor variabilidad puede observarse que: i) Los contenidos de $\mathrm{P}$ medidos son mucho menores que los aplicados en cada tratamiento probablemente por efecto de la fijación (precipitación con calcio) y del factor de recubrimiento del método analítico empleado $(11,22)$; ii) el $\mathrm{pH}$ del sustrato disminuye con el incremento de la dosis (1) pero sólo a dosis superiores a $40 \mathrm{~g}$ de $\mathrm{P} / \mathrm{m}^{2}$ se alcanzan los niveles óptimos; iii) los valores de pH se corresponden con los contenidos de P y iv) la capacidad de retención 
del sustrato es dependiente de la dosis de superfosfato aplicada.

Tabla 3. Medias por tratamiento de los contenidos de $P$ asimilable y $\mathrm{pH}$ del sustrato, registrados a los 13 y 27 días posteriores al momento de fertilización. (Letras distintas indican diferencias significativas $(P<0.05)$ según test de Duncan).

\begin{tabular}{ccc}
\hline $\begin{array}{c}\text { Dosis de } \mathrm{P} \\
\mathrm{g} / \mathrm{m}^{2}\end{array}$ & $\mathrm{ppm}-\mathrm{P}$ & $\mathrm{pH}$ \\
\hline 10 & $120 \mathrm{~cd}$ & $6,6 \mathrm{ab}$ \\
20 & $72 \mathrm{~d}$ & $6.9 \mathrm{ab}$ \\
40 & $113 \mathrm{~cd}$ & $6,6 \mathrm{ab}$ \\
60 & $187 \mathrm{bc}$ & $6.5 \mathrm{ab}$ \\
80 & $199 \mathrm{~b}$ & $6.3 \mathrm{~b}$ \\
150 & $357 \mathrm{a}$ & $6,1 \mathrm{~b}$ \\
c.v. & 28,1 & 3,8
\end{tabular}

El comportamiento que se observa a dosis bajas de superfosfato es similar al encontrado en turbas que según Gibson y Pili (8) se relaciona con los tenores de $\mathrm{NH} 4+$.

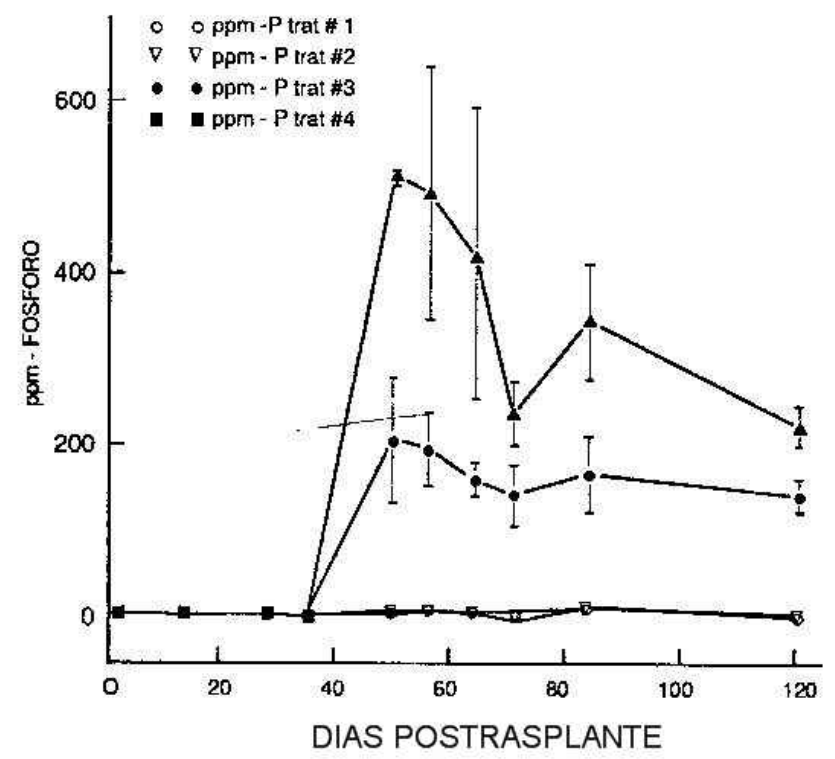

Figura 1. Variación de la disponibilidad de $\mathrm{P}$ en el sustrato durante el ciclo de cultivo. Las líneas verticales presentan 2 ES. 


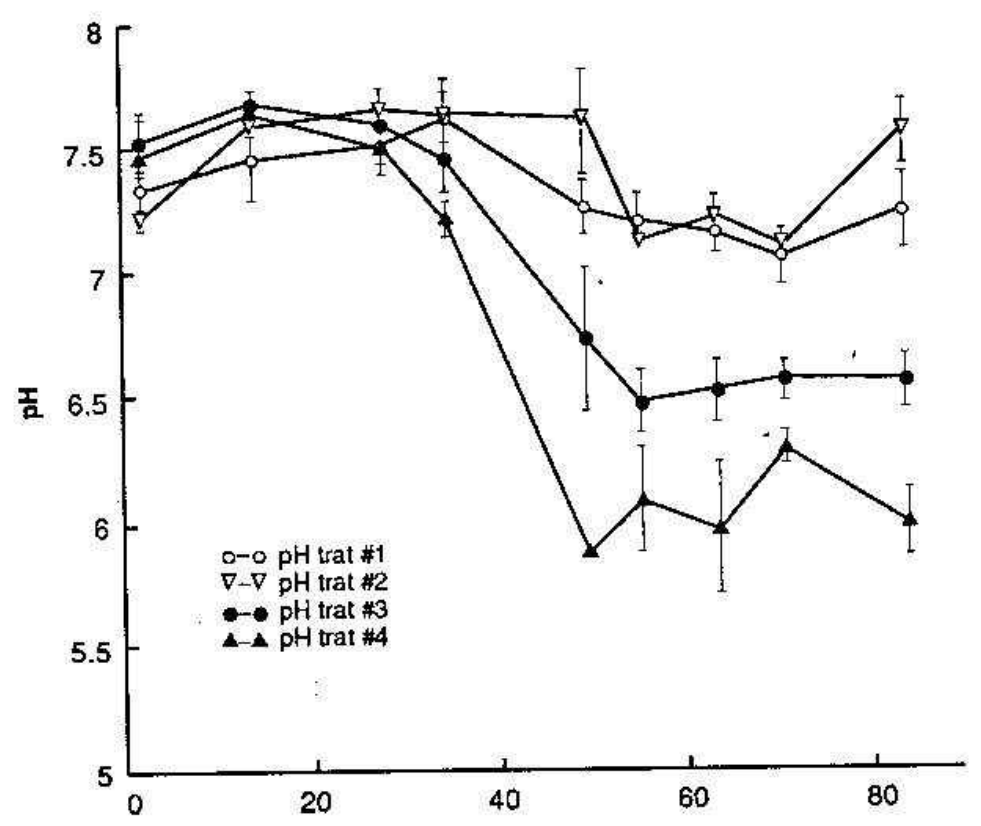

Figura 2. Evolución del pH del sustrato durante el ciclo de cultivo. Las líneas verticales representan $2 \mathrm{ES}$.

Efecto sobre el contenido de $\mathbf{P}$ en hojas: En la Figura 3 se informan los niveles de $\mathrm{P}$ total alcanzados en hojas cuando las dosis de $\mathrm{P}$ se incrementan de 10 a 150 g de $\mathrm{P} / \mathrm{m}^{2}$ y en dos cosechas posteriores a la fertilización (13 y 27 días); encontrándose diferencias significativas entre fechas $(\mathrm{P}<0,001)$ y para ambas entre tratamientos $(\mathrm{P}<0,05)$. Los valores numéricos de los niveles foliares alcanzados, no pueden ser comparados con rangos críticos por no encontrarse citas, para esta variedad y condiciones experimentales, en la bibliografía consultada; no obstante son más altos que los niveles máximos informados para otras variedades cultivadas a campo $(9,12,19)$ y en general superan el valor óptimo de McKay (0,50\%) (10).

Efectos sobre número, rendimiento y distribución de minitubérculos: La máxima producción obtenida es de $4.3 \mathrm{~kg}$ de minitubérculos $/ \mathrm{m}^{2}$ (Figura 4) y 385 minitubérculos $/ \mathrm{m}^{2}$ (Figura 5), siendo semejante a las obtenidas por Wiersema en algunas experiencias a partir de semilla botánica (21); sin embargo es menor a la esperada en función de ensayos preliminares (9 kg de minitubérculos $/ \mathrm{m}^{2}$ y 1000 minituberculos $/ \mathrm{m}^{2}$ datos no publicados) y de la máxima esperada para el sistema de producción propuesto por Wiersema (12 kg y 1242 minitubérculos/m²) (21). 
Revista Latinoamericana de la Papa. (1993). 5/6:89-102

El rendimiento máximo se obtuvo con una dosis de $20 \mathrm{~g}$ de $\mathrm{P} / \mathrm{m}^{2}$ observándose un efecto perjudicial a dosis mayores, este efecto depresivo en la producción ha sido informado para suelos con altos contenidos de P (16). Echevarría (7) encontró para esta variedad (papa consumo) un efecto depresivo importante a partir de un nivel de disponibilidad de $\mathrm{P}$ en suelo de 5 ppm. siendo éste mucho más bajo que el observado en este experimento (100 ppm)

En cuanto a la composición de la producción (Figura 5) se observa que la fracción de minitubérculos de peso comprendido entre 5 y 40 g alcanza el 53$54 \%$ del total para las menores dosis. Exceptuando los resultados correspondientes a la dosis de $80 \mathrm{~g}$ de $\mathrm{P} / \mathrm{m}^{2}$ por no ser consistentes, las medias de producción en peso, número total y número de fracción de 20-40 g de minitubérculos cosechados por $\mathrm{m} 2$ muestran tendencias paralelas con un valor máximo para la dosis de $20 \mathrm{~g}$ de $\mathrm{P} / \mathrm{m}^{2}$.

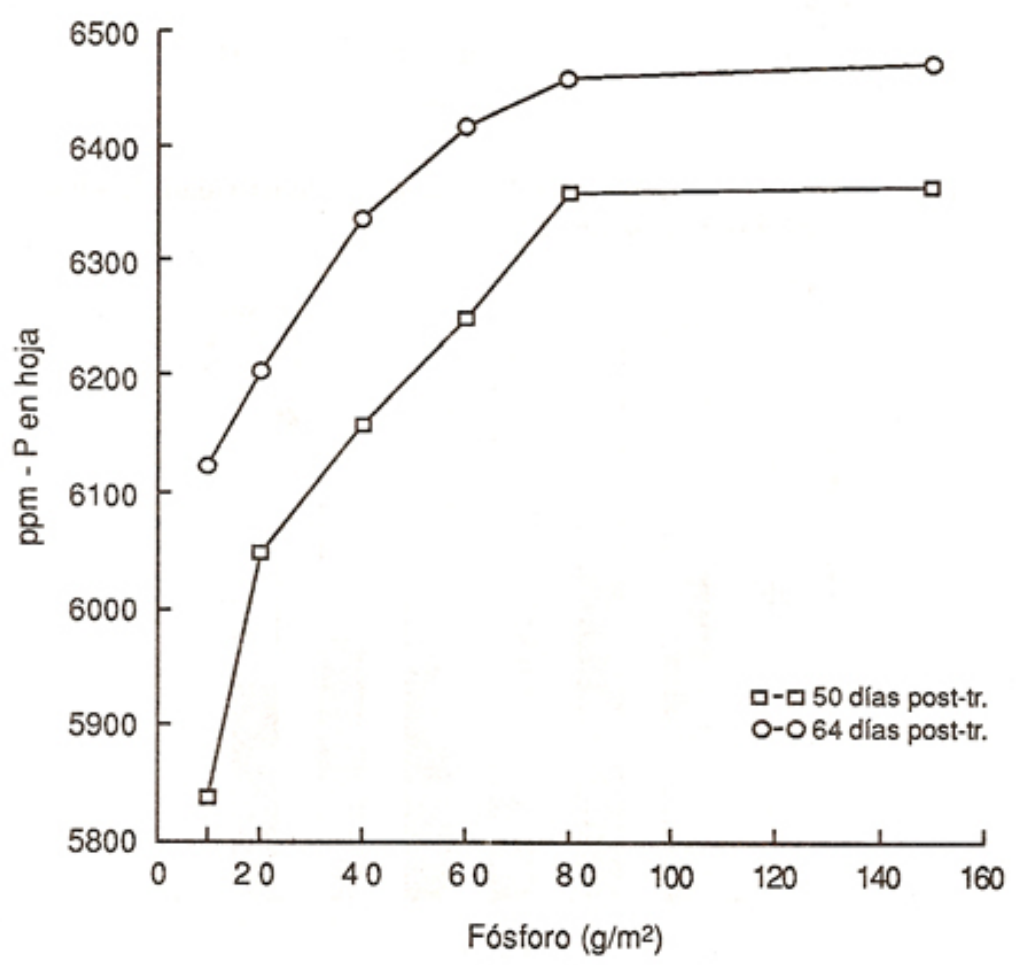

Figura 3. Efecto de distintas dosis de P sobre el contenido de $P$ total en hojas. 


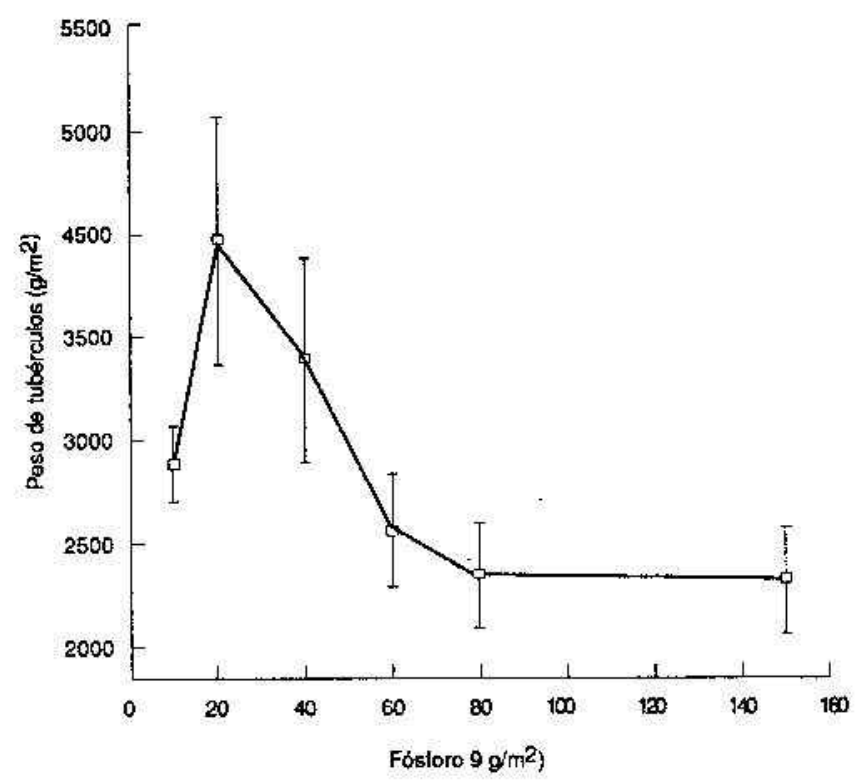

Figura 3. Efecto de distintas dosis de $P$ sobre la productividad. Las líneas verticales representan $2 \mathrm{ES}$.

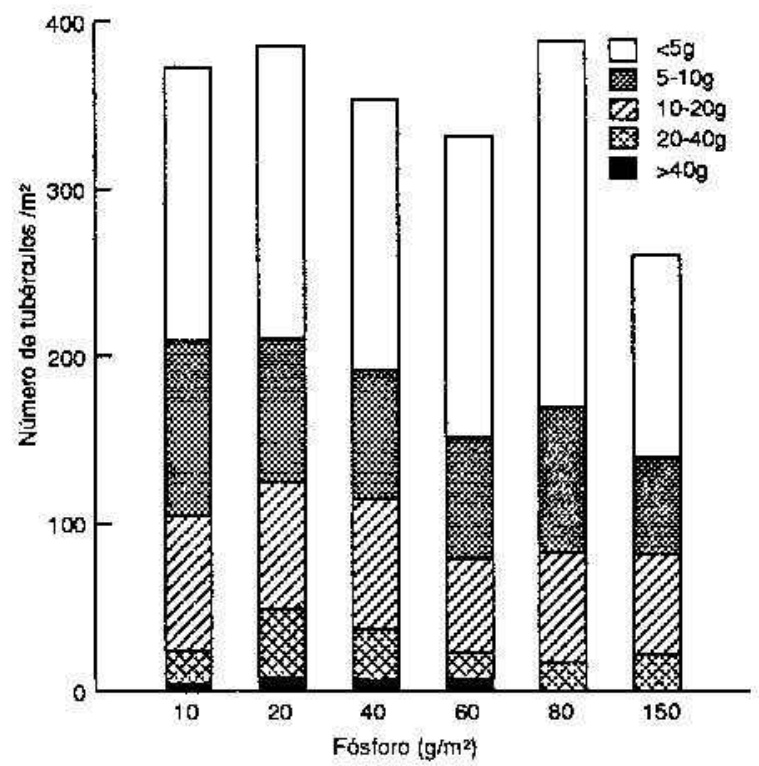

Figura 4. Efecto de distintas dosis de $\mathbf{P}$ sobre el número de minitubérculos cosechados y su distribución según diferentes intervalos de peso. 
El mayor rendimiento y número máximo de minitubérculos se corresponde con contenidos de $\mathrm{P}$ de 71 -72 ppm en sustrato y de 0,60-0,62\% en hojas a los 50 y 64 días posteriores al trasplante. A pesar que los niveles de disponibilidad en el sustrato para ambas fechas muestran mejor correlación con los datos de producción que los niveles foliares, la practicidad analítica en la determinación de los segundos sustenta el empleo de 0,60\% de P/peso seco en hojas a los 50 días posteriores del trasplante como índice pronóstico de suficiencia o nivel crítico.

La proximidad entre el valor numérico de la mejor dosis (20 g) y el de la absorción estimada bajo la hipótesis planteada en la discusión de la experiencia 1 (17 $\mathrm{g}$ de $\mathrm{P}$ para una producción de 4,3 kg de minitubérculos $/ \mathrm{m}^{2}$ ) permite sostener como correcto el mecanismo de retención propuesto. La fijación química del $\mathrm{P}$ al sustrato (precipitación como fosfatos cálcicos) produce su inmovilización sin pérdida de disponibilidad, en consecuencia la capacidad de reserva del sustrato es incrementada, posibilitando además, controlar el factor intensidad dentro de algún valor determinado.

\section{CONCLUSIONES}

Bajo las condiciones experimentales en que se llevó a cabo este experimento se puede concluir que: a pesar que el $\mathrm{pH}$ requerido por el cultivo se alcanzó con aplicaciones de P (como superfosfato triple) superiores a $40 \mathrm{~g} / \mathrm{m}^{2}$, éstas no mejoraron la productividad del sistema. A dosis iguales o mayores a la mencionada se observa un efecto perjudicial tanto en el peso como en el número de minitubérculos de peso deseado cosechados $/ \mathrm{m}^{2}$ demostrándose una tendencia a la producción de minitubérculos de bajo peso con el incremento de la dosis de P.

El sustrato empleado posee un $\mathrm{pH}$ inicial alto y una escasa capacidad reguladora de $\mathrm{pH}$ y $\mathrm{P}$. El superfosfato triple aplicado se fija químicamente mejorando la fertilidad en ambos factores: capacidad e intensidad.

Una dosis de $20 \mathrm{~g} / \mathrm{m}^{2}$ de $\mathrm{P}$ a partir de superfosfato triple es una adecuada aproximación a la obtención del régimen de fertilización ideal para la época, pudiendo ser corregida si previamente se ajusta el $\mathrm{pH}$ dentro de los valores óptimos y se trabaja en relación al balance nutricional con $\mathrm{N}$ y K.

El análisis de $\mathrm{P}$ asimilado permite concluir que se puede tomar el nivel foliar de $0,60 \%$ (materia seca) como índice pronóstico de suficiencia o nivel crítico por su estrecha relación con los datos de producción. 


\section{AGRADECIMIENTO}

Los autores agradecen el apoyo brindado en los análisis químicos por el Ing. Qco. Horacio Avila y la Qca Beatriz Aguilar.

\section{REFERENCIAS BIBLIOGRÁFICAS}

1. Alben, A.0. 1961. Effects of ammonium nitrate triple superphosphate and muriate of patash on reation of Yahola loam in a factorial fertilizer experiment. Soil Sci.92:1-14.

2. Bunt, A.C. 1986. Problems in the analysis of organic and lighweight potting substrats. Hort. Science. 21: 229-231.

3. Burba, J.L.; Fontan, H.M.; Buteler, M.I.; Blanco, M.P.; Saluzzo, J.A.; Moriconi, D.N. 1986. Programa Regional de Producción de Semilla Básica de Papa - Sede Córdoba. En: Actas IX Reunión Nacional de la Asoc. Arg. de Horticultura Y II Latinoamericana. La Plata, Argentina. $65 \mathrm{p}$.

4. Dallari L.R; Buteler; A.B. Giorgetta, A.B. 1989. Evaluación y obtención de sustratos óptimos para multiplicación en invernáculo de plantas de papa libres de virus: 1 Caracterización físico-química de los materiales. En: Actas XII Congreso Argentino de Horticultura. Resúmenes. Santa Fe. Argentina. 67 p.

5. De Boodt, M.; Verdonck, O. 1972. The physical properties of substrats in horticulture. Acta Hort. 26:37-44.

6. Delazari, P,C.; Zangrande, M.B.; Filho, N.D. 1989. Rendimento económico de batata em funcao do nitrogênio. fósforo e potassio em solos do Espirito Santo. Hort. Bras. 7:24-26.

7. Echevarría, H. 1988. Algunas consideraciones sobre suelos y fertilización en el cultivo de papa. En: IV Curso Internacional de Producción y Fiscalización en Semilla de Papa. Córdoba. Argentina. $19 \mathrm{p}$.

8. Gibson, C.J; Pill, W.G. 1983. Effects of preplant phosphorus fertilization rate and of nitrate and ammonium liquid feeds on tomato grown in peat-vermiculite. J. Amer. Soc. Hort. Sci. 108:1007-1011. 
9. Krentos V.D.; Orphanos, P.J. 1979. Nitrogen phosphorus and potassium fertilizers for potatoes in Cyprus. J. Agric. Sci. Camb. 92:645-661.

10. MacKay, D.C.; MacEachern, C.R; Bishop, RE 1966. Optimun nutrient levels in potato leaves (Solanum tuberosum L.). Soil Sci. Soc. Amer. Proc. 30:73-76.

11. Markus, D.K. 1986. Spurway/acid extraction procedures. Hort Science 21: 217-222p.

12. Paula, M.B.; Fontes, P.C.R.; Nogueira, F.D. 1986. Produção de materia seca e absorção de macronutrientes por cultivares de batata. Hort. Bras. 4:10-16.

13. Paula, M.B.; Fontes, P.C.R.; Nogueira, F.D. 1986. Absorção de micronutrientes por cultivares de batata em presença e ausencia de adubação. Hort.. 4: 3-8.

14. Prasad, M. 1980. Retention of nutrients by peals and wood wastes Scientia Horl, 12:203-209.

15. Saluzzo, J; Collino, D.; Dallad, J.P; Avila, A. 1989. Aumento de la eficiencia en el sistema de propagación de semilla pre-básica de papa. En: Actas XII Congreso Argentino de Horticultura. Santa Fe Argentina. $49 \mathrm{p}$.

16. Simpson, R. 1961. Factors influencing uptake of phosphorus by crops in Southeast Scotland. Soil Science 92:1-14.

17. Tisdale, S.L., Nelson, W.L. 1970. Fertilidad de los suelos y fertilizantes. Ed. Montoner y Simón. Barcelona España. 760 p.

18. Warncke,D.D. 1986. Analyzing greenhouse growth media by the saturation extraction method. Hort Science 21:223-225.

19. White, R.P.; Munro, D.C.; Sanderson, J.B. 1974. Nitrogen, potassium, and plant spacing effects on yield, tuber size, specific gravity, and tissue N, P, and K of Netted geni potatoes. Can. J. Plant Sci. 54: 535539.

20. Wiersema, S.G. 1984. The production and utilization of seed tubers derived from true potato seed. Ph.D Thesis. University of Reading. Reading. United Kingdom. 229 p.

21. Wiersema, S.C. 1986. A method for producing seed tubers from true potato seed. Potato Res. 29:225-237.

22. Wolf, B. 1982. An improved universal extracting solution and its use 
for diagnosing soil fertility. Commun. Soil Sci. Plant Anal. 13:10051033.

23. Wolf, B. 1982. A comprehensive system of leaf analysing and its use for diagnosing crop nutrient status. Commun. Soil Sci. Plant Anal. 13: 1035-1059.

24. Yeager,T.H.; Wright, R.D. 1982. Phosphorus requirement of llex crenata Thunb. cv. Helleri grown in a pine bark medium. J. Amer. Soc. Hort. Sci. 107: 558-562. 